\title{
Cardiac Regenerative Medicine: The Potential of a New Generation of Stem Cells
}

\author{
Elena Cambria ${ }^{a, b} \quad$ Julia Steiger ${ }^{a, b} \quad J u l i a$ Günter ${ }^{a, b} \quad$ Annina Bopp ${ }^{a, b} \quad$ Petra Wolint $^{a, b}$ \\ Simon P. Hoerstrup ${ }^{a, b, c, d}$ Maximilian Y. Emmert ${ }^{a, b, c, d}$ \\ a Institute for Regenerative Medicine, University of Zurich, Zurich, Switzerland; \\ ${ }^{b}$ Division of Surgical Research, University Hospital of Zurich, Zurich, Switzerland; \\ ${ }^{\mathrm{c}}$ Heart Center Zurich, University Hospital of Zurich, Zurich, Switzerland; \\ ${ }^{d}$ Wyss Translational Center Zurich, Zurich, Switzerland
}

\section{Keywords}

Allogeneic stem cell · Bone marrow - Stem cell transplantation - Stem cells - Cardiac stem cell therapy . Cardiac progenitors · Cardiopoietic cells · Cardiac stem cells $\cdot$ Embryonic stem cells $\cdot$ Induced pluripotent cells

\section{Summary}

Cardiac stem cell therapy holds great potential to prompt myocardial regeneration in patients with ischemic heart disease. The selection of the most suitable cell type is pivotal for its successful application. Various cell types, including crude bone marrow mononuclear cells, skeletal myoblast, and hematopoietic and endothelial progenitors, have already advanced into the clinical arena based on promising results from different experimental and preclinical studies. However, most of these so-called first-generation cell types have failed to fully emulate the promising preclinical data in clinical trials, resulting in heterogeneous outcomes and a critical lack of translation. Therefore, different next-generation cell types are currently under investigation for the treatment of the diseased myocardium. This review article provides an overview of current stem cell therapy concepts, including the application of cardiac stem (CSCs) and progenitor cells (CPCs) and lineage commitment via guided cardiopoiesis from multipotent cells such as mesenchymal stem cells (MSCs) or pluripotent cells such as embryonic and induced pluripotent stem cells. Furthermore, it introduces new strategies combining complementary cell types, such as MSCs and CSCs/CPCs, which can yield synergistic effects to boost cardiac regeneration.

(C) 2016 S. Karger GmbH, Freiburg

Elena Cambria and Julia Steiger contributed equally to this article.

\section{Introduction}

According to the World Health Organization (WHO), an estimated number of $31 \%$ of all deaths in 2012 were attributed to cardiovascular diseases (CVDs) [1]. As an entity of CVD, myocardial infarction (MI) causes the death of millions of cardiomyocytes, and further triggers a remodeling process that can finally lead to chronic heart failure (HF). Unfortunately, current therapeutic strategies are only able to delay the progress of the disease but not to stop or to reverse it [2]. In particular, the socio-economic burden created by the increasing number of incurable ischemic heart disease accentuates the substantial need for the development of new curative approaches for cardiac repair $[2,3]$.

Regenerative medicine is a rapidly emerging field aiming to repair the diseased tissue. Stem cell therapy has been proposed as a novel approach for the treatment of HF, either in the acute state after MI or in the chronic setting. The concept of stem cell delivery to the heart via different routes has been proven feasible and safe in several preclinical and clinical trials. Moreover, there is evidence that stem cell-based therapies are capable of moderately improving cardiac function in diseased hearts. However, clinical outcomes regarding the efficiency of the therapies have been heterogeneous so far and could not fulfill the expectations [3]. Several parameters need to be considered and optimized for the development of an efficient cell therapy. These include the delivery route, the timing, the dose, and in particular the cell type [4].

An interesting cell source is the bone marrow as it contains different cell types, including bone marrow mononuclear cells (BMMNCs) and their subpopulations. The use of bone marrowderived cells is advantageous because these can be obtained in clinically relevant numbers and they have been proven to be safe. BMMNCs as well as hematopoietic (HPCs) and endothelial pro-

\section{KARGER}

Fax +497614520714

\section{(๑) 2016 S. Karger GmbH, Freiburg}

$1660-3796 / 16 / 0434-0275 \$ 39.50 / 0$
Maximilian Y. Emmert, $\mathrm{MD}, \mathrm{PhD}$

Institute for Regenerative Medicine (IREM) University of Zurich

Moussonstrasse 13, 8044 Zurich, Switzerland maximilian.emmert@usz.ch 
genitor cells (EPCs) have been isolated and applied for cardiac regeneration [5]. However, the outcomes in numerous clinical trials were heterogeneous [6]. Skeletal myoblasts (SMs) were one of the first cell types tested for cardiac regeneration in humans. Unfortunately, their differentiation into myotubes was not accompanied by electrical coupling to resident cardiomyocytes and, importantly, a side effect of the SM transplantation was the occurrence of ventricular arrhythmias [7]. Bone marrow-derived mesenchymal stem cells (BMMSCs) have also been suggested because of their favorable safety profile, their immunoprivileged state, and their secretome [8]. Indeed, there are several performed and ongoing preclinical and clinical trials showing promising results in terms of safety $[9,10]$.

Despite the auspicious regenerative properties of mesenchymal stem cells (MSCs), the interest has shifted within the last few years towards cell types that can directly contribute to cardiac regeneration, such as cardiac stem (CSCs) and progenitor cells (CPCs). While MSCs are supposed to aid in cardiac repair through paracrine signaling and differentiation into different cell types, stem cell therapy with CSCs/CPCs aims to repair the diseased myocardium by matching the target organ and replacing the damaged and lost cardiomyocytes. The heart has limited regenerative capacities that can be enhanced by the addition of suitable cell types such as MSCs [11]. However, little is known on how far this regeneration can be pushed. Therefore, next-generation cell types, such as CSCs/CPCs and lineage-specified cells, raised the hope to improve regenerative strategies for heart repair.

This review article summarizes state-of-the-art cardiac stem cell therapy approaches. In particular, it gives an overview of CSCs/ $\mathrm{CPCs}$ and their performance in preclinical and clinical trials. Moreover, a focus will be on lineage-specified cells obtained via guided cardiopoiesis from different multipotent and pluripotent cell sources. Finally, the combination of cardiac cell types with complementary cell types, such as MSCs, will be highlighted as a potential strategy for the further enhancement of current therapies that involve a single cell type.

\section{Cardiac Stem and Progenitor Cells}

Stem cell therapy with CSCs/CPCs is relatively novel compared to cell therapies using more traditional cell types, such as MSCs and other bone marrow cell populations. The regenerative potential of the human heart has been discovered only recently and is still controverted. It has been shown by different groups and with different techniques that the human heart has a regeneration turnover of about $1 \%$ per year [12]. However, the origin of this regeneration and the related mechanisms are not fully understood yet. It is not clear whether human cardiomyocytes truly proliferate and/or dedifferentiate [12] and whether real stem cells, which are capable of self-renewal and differentiation, exist in the human heart. The presence of progenitor cells has been repeatedly suggested. Nevertheless, their roles and mechanisms remain to be uncovered. CSCs/CPCs can be isolated from heart biopsies that are performed during interventional surgical procedures. They are defined by their multipotency and clonogenicity as well as by the presence of common stem cell markers, such as c-kit and Sca-1, and cardiac markers, such as Isl-1, Nkx2.5 and GATA4 [13]. Cells that migrate from cultured cardiac explants can form cardiospheres, which can then be dissociated to obtain cardiospherederived cells (CDCs) [14].

The investigation of CSCs/CPCs is still at its infancy with only a limited number of in vivo studies and a few clinical trials. Several studies have been conducted in vitro to explore the mechanisms of cardiac regeneration. Remarkably, it has been shown that CPCs expressing Isl-1, Nkx2.5, and GATA4 are present in the postnatal mouse, rat, and human heart and that they differentiate into cardiomyocytes in vitro [15].

Preclinical trials have also been conducted with encouraging results in small and large animal models. Interestingly, the origin of the investigated CPCs includes both autologous and allogeneic cells. Cardiospheres and CDCs have been transplanted into pigs with promising results [16-19]. Allogeneic CDCs have been shown safe (no microvascular obstruction) and efficient (decrease in infarct size and adverse remodeling compared to controls) when delivered intracoronary at different doses (from 5 to 10 million cells) into pigs [17].

Several ongoing clinical trials are also demonstrating safety, feasibility, and promising results concerning efficacy. The two most famous clinical trials are the Cardiac Stem Cell Infusion in Patients With Ischemic Cardiomyopathy trial (SCIPIO, NCT00474461) and the CArdiosphere-Derived aUtologous stem CElls to reverse ventricUlar dysfunction trial (CADUCEUS, NCT00893360).

SCIPIO is a phase I, first-in-man, randomized study that investigates intracoronary transplantation of autologous c-kit+ CSCs into 33 patients (20 treated and 13 controls) with ischemic cardiomyopathy. Significant increase in left ventricular ejection fraction (LVEF) and decrease in infarct size were shown 4 and 12 months after cell delivery. An improvement in LV function was shown by cardiac magnetic resonance imaging (cMRI) [20].

The CADUCEUS trial is also a phase I, randomized clinical trial that involved 17 patients ( 9 treated and 8 controls). It addresses the intracoronary administration of autologous CDCs at escalating doses of 12.5-25 million cells 1.5-3 months after acute myocardial infarction. At the 6-month follow-up, the cell therapy was shown to be safe (no cardiac tumors, major adverse cardiac events or death), with promising results regarding efficacy as measured by MRI (significant decrease in scar mass, increase in viable heart mass, and contractility compared to controls). These preliminary results were found to be consistent with cardiac regeneration 1 year after treatment [21].

Another clinical trial that addresses the use of CSCs for cardiac repair is the AutoLogous Human CArdiac-Derived Stem Cell to Treat Ischemic cArdiomyopathy trial (ALCADIA, NCT00981006). This phase I study was initiated in 2010 and aimed at assessing the safety and efficacy of autologous CSC delivery with controlled release of basic fibroblast growth factor (bFGF) in HF patients. The treatment appeared to be safe and 
showed decreased scar size together with increased LVEF 6 months after implantation.

To date, only a few clinical trials investigate the use of allogeneic cardiac cells. These are the Allogeneic Heart Stem Cells to Achieve Myocardial Regeneration trial (ALLSTAR, NCT01458405) and the recent CAREMI trial (NCT02439398). The phase I/II ALLSTAR study was started in 2012, and patients are currently recruited. The goal is to evaluate the effect of allogeneic CDCs on scar size after acute MI. The CAREMI trial is a first-in-man, randomized phase I/ II study that aims to investigate the intracoronary injection of different doses of allogeneic CSCs.

Cardiac repair through CSCs/CPCs therapies only begins to be explored. Although initial studies yielded promising results, these need to be confirmed in further clinical trials with larger patient numbers and longer follow-up times.

\section{Guided Cardiopoiesis and Direct Reprogramming}

\section{MSCs}

While the aforementioned studies all investigate CSCs/CPCs that are obtained from cardiac biopsies, other studies address the use of lineage-specified cardiopoietic cells. MSCs are one of the possible cell sources for guided cardiopoiesis. They have repeatedly been suggested as an immunoprivileged and therefore valuable clinical cell source for cardiac repair [8]. MSCs are multipotent stromal cells that are mainly characterized by their adherence properties, a distinct surface marker profile composed of markers such as CD29, CD44, CD105, CD73 and CD90, paracrine signaling, and the ability to differentiate into the adipogenic, chondrogenic and osteogenic lineage $[22,23]$. A subset of MSCs can also differentiate into cardiomyocytes under specific conditions in vitro [22-24]. Due to their enormous expansion rate and immunomodulatory properties, MSCs are considered as a potential candidate for both autologous and allogeneic stem cell therapy. Guided cardiopoiesis of autologous BMMSCs has been proposed as a next-generation approach for targeted cardiac repair $[3,5]$. Supported by preclinical studies, the translation into distinct clinical settings, aiming to assess the therapeutic potential for patients suffering from MI or HF, was proven to be safe, feasible, and partially efficient as shown by improved LVEF [25]. In the phase II Cardiopoietic stem Cell therapy in heart failURE trial (C-CURE, NCT00810238), cardiopoietic stem cells were derived from BMMSCs that were treated with cardiogenic growth factors. These cells were injected endomyocardially into HF patients. Safety, feasibility, and efficacy were assessed 6 months and 2 years after treatment. The results were encouraging and showed an increase in LVEF $[5,26]$. They lead to the two ongoing phase III Congestive Heart failure Cardiopoietic Regenerative Therapy trials (CHART-1 and CHART-2, NCT01768702) $[6,27,28]$. Nevertheless, the differentiation capacity of MSCs should be investigated in more detail.

\section{Embryonic Stem Cells (ESCs)}

Although multipotent cells like MSCs possess a considerable potential for lineage specification, ESCs depict the gold standard for cardiomyocyte generation [13]. ESCs are blastocyst-derived cells that are pluripotent, meaning that they can differentiate into any cell type of the adult human body. ESC-derived cardiomyocytes offer the possibility to directly contribute to heart contractility without any reprogramming-induced genomic alterations [23, 29]. However, ESCs have not been considered for clinical trials for a long time due to several significant limitations, such as the propensity to form teratomas, potential immunological rejection after injection in vivo as well as substantial ethical concerns regarding the use of human ESCs [30, 31]. To limit potential teratoma formation, genetic selection of differentiated ESCs or the differentiation of ESCs into cardiomyocytes has been suggested for cardiac stem cell therapy [32-35]. In several preclinical studies entailing the transplantation of non-teratogenic human ESC-derived cardiac progenitors into rat and non-human primate models of myocardial infarction, Menasché et al. [36] have confirmed that these cells are effective in improving cardiac function. The procedure has yielded remarkably positive outcomes concerning cardiac differentiation as well as improvement in LV function. Moreover, it was found that epicardial delivery of ESC-derived cardiac progenitors embedded in a fibrin patch is far more effective than multiple intramyocardial injections with regard to cell engraftment and functional outcome. These data have paved the way for a translational phase I clinical trial with the goal to prove feasibility and safety in 6 patients. The world-first and ongoing Transplantation of Human Embryonic Stem Cell-derived Progenitors in Severe Heart Failure trial (ESCORT, NCT02057900) is a unique proof-of-concept study, which was initiated in 2013. Patients with ischemic HF epicardially receive human ESC-derived CD15+ Isl-1+ progenitors that are embedded into a fibrin patch, in addition to coronary artery bypass graft surgery and/or a mitral valve procedure. The first case of one of the patients who has reached the 3-month follow-up time point showed that LVEF improved from 26 to $36 \%$. No complications such as arrhythmias, tumor formation or immunosuppression-related adverse events could be observed. These data demonstrate the feasibility of transferring clinical-grade human ESC-derived progenitor cells embedded in a fibrin patch to the diseased myocardium and the relatively good tolerance of these cells. However, a more extensive follow-up as well as an increased number of patients will allow further documentation of safety and efficacy of human ESCs in cardiac regenerative medicine [37].

\section{Induced Pluripotent Stem Cells (iPSCs)}

iPSCs represent a possible solution to overcome the ethical and immunological issues raised by ESCs. Indeed, iPSCs recapitulate the properties of ESCs although they are derived from adult somatic cells. Originally, iPSCs were obtained by retroviral reprogramming with gene cocktails, but novel safer nonviral techniques 
include the use of reprogramming proteins, small molecules, or miRNAs [12]. It has been shown that iPSCs can differentiate into cells of the three germ layers including cardiomyocytes [38]. Human iPSCs-derived cardiomyocyte sheets have been implanted in a porcine model of ischemic cardiomyopathy [39]. The cells could be detected up to 8 weeks after implantation, but the survival was low on the long term. No teratoma formation was observed, and the cardiac function was improved. Recently, human iPSCs have been differentiated into the three cardiac lineages (cardiomyocytes, smooth muscle cells, and endothelial cells) and have been transplanted in a porcine model of MI [40]. Cell engraftment and improved cardiac function could be observed without the appearance of ventricular arrhythmias. Reprogramming of fibroblasts into expandable induced CPCs and differentiation of pluripotent stem cells can provide an increased access to CPCs [41, 42]. Despite these positive preliminary results, important safety concerns such as rejection and teratoma formation still need to be thoroughly addressed before iPSCs can be used in a clinical setting.

\section{Direct Reprogramming}

Although the generation of cardiomyocytes from pluripotent stem cells bears great potential for cardiac regeneration, there are still severe concerns regarding their safety. In particular, the elimination of remaining pluripotent cells prior to implantation is a critical step, given that these cells could induce teratoma formation. The direct reprogramming of somatic cells into other cell types, such as cardiomyocytes, circumvents the pluripotent state and thus eliminates the issue of teratoma formation. The technique of traditional reprogramming using a cocktail of transcription factors inspired the direct reprogramming of one somatic cell type into another [43].

Over the last decade, it has been shown that murine fibroblasts can be transdifferentiated into functional cardiomyocyte-like cells using transduction with specific cocktails of transcription factors $[44,45]$. Interestingly, the relatively low direct reprogramming efficiency of fibroblasts in vitro was improved when the transcription factor cocktail was applied directly into the infarction zone in mice $[12,46]$. The in vivo transduction of resident fibroblasts resulted in improved cardiac function and decreased scar size [12]. Nevertheless, the cocktails successfully used in murine cells could not transform human fibroblasts into cardiomyocyte-like cells, whereas other compositions of defined transcription factors were able to do so [47]. De novo generation of cardiomyocytes would constitute an excellent tool for cardiac regeneration. However, the field of direct reprogramming is only in its infancy, and many issues need to be overcome. Despite the persistent low efficiency, the cardiomyocyte-like cells obtained in vitro are still immature in their differentiation state and need to undergo additional maturation steps to be considered adult cardiomyocytes. Once it can be shown that cardiomyocytes generated via direct reprogramming are functional in vitro, their safety and efficacy in preclinical HF models still needs to be evaluated [47]. An even more elegant solu- tion for heart regeneration would be the direct in vivo conversion of resident cardiac fibroblasts into cardiomyocytes after cardiac injury. This approach has been shown to be feasible and to improve cardiac function in a murine model. However, these investigations were performed using retroviral vectors, which bear the risk of non-target cell transduction as well as of non-controllable integration into the genome, resulting in insertional mutagenesis [43]. Given that cardiac direct reprogramming of murine and human fibroblasts needs different transcription factor cocktails [47], it is necessary to prove the in vivo direct reprogramming and safety also in large animal models to finally enable clinical translation in the long run.

\section{Combination Therapies}

Although intensive research is conducted to find the ideal cell type for cardiac stem cell therapy, it has been suggested that cardiac regeneration could be achieved through the combination of several cell types with complementary properties.

Lately, the combination of MSCs and CSCs/CPCs has yielded interesting results. Based on the rationale that MSCs stimulate CSC proliferation [48], Williams and co-workers [49] hypothesized that combining MSCs and CSCs/CPCs has a greater effect on cardiac regeneration than delivering either cell type alone. Human MSCs and c-kit+ CSCs were isolated from bone marrow aspirates and endomyocardial biopsies, respectively, and were injected intramyocardially either alone or in combination into an immunosuppressed swine model 14 days after MI. Hemodynamics measurements, cMRI and histology showed that the combination therapy significantly enhanced scar size reduction, LV function and cell engraftment compared to the treatment with either cell type alone. The synergistic effect of MSCs and CSCs has also been shown recently in a similar study in a non-immunosuppressed porcine model of chronic HF [50]. Autologous BMMSCs were delivered transendocardially either alone or in combination with autologous c-kit+ CSCs 3 months after ischemia/reperfusion injury. While scar size decreased and viable tissue increased in both cell-treated groups compared to placebo, cardiac function improved only in the combination group, as measured by LVEF, stroke volume, cardiac output, regional diastolic strain rate and endothelial function 3 months after treatment [50].

In the clinical setting, the CONCERT-HF trial (NCT02501811) is currently recruiting an estimated number of 144 patients with ischemic cardiomyopathy. This phase II randomized, placebo-controlled study aims to assess the feasibility, safety, and efficacy of transendocardial injection of autologous BMMSCs and c-kit+ CSCs either in combination or alone.

Innovative tools have recently emerged in the field of combinatorial cell therapy and include so-called CardioChimeras (CCs) and 3D-microtissues (3D-MTs) or spheroids. CCs were formed by ex vivo viral cell fusion between MSCs and CPCs and were allowed to undergo clonal expansion [51]. Two different clones with enhanced proliferation and survival properties (CC1 and CC2) were 
Fig. 1. Evolution of first-generation, next-generation and combined stem cell-based approaches for cardiac regeneration (schematic overview with representative cell types for BMMNCs, ESC-derived cardiomyocytes, CCs). BMMNCs $=$ Bone marrow mononuclear cells; HPCs = hematopoietic stem cells; SMs = skeletal myoblasts; EPCs = endothelial progenitor cells; MSCs = mesenchymal stem cells; ESCs = embryonic stem cells; iPSCs $=$ induced pluripotent stem cells; $\mathrm{CSCs} / \mathrm{CPCs}=$ cardiac stem and progenitor cells; cpMSCs = cardiopoietic stem cells; $\mathrm{CCs}=$ cardiochimeras; $\mathrm{MTs}=3 \mathrm{D}$-microtissues .

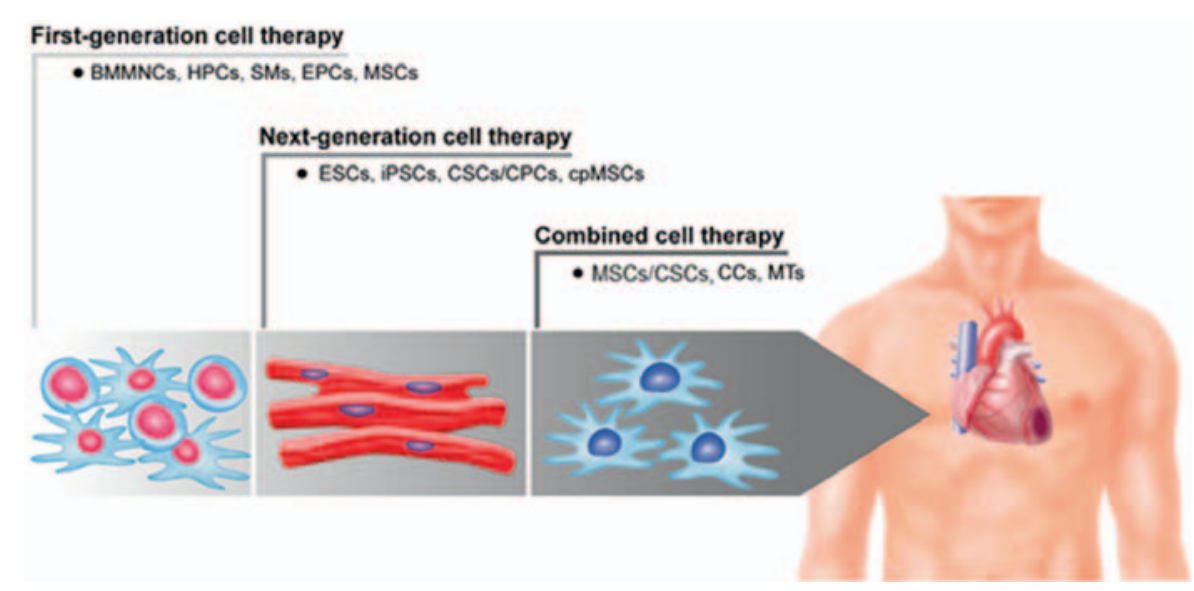

chosen for further comparison with individual cell and combinatorial therapies in a mouse MI model. LV anterior wall thickness was improved by CCs 4 weeks after MI, but the improvement was only maintained by $\mathrm{CC} 1$ after 18 weeks. Functional improvements were also maintained by both the CCs and CPC+MSC groups up to 18 weeks. Interestingly, infarct size was only decreased by CCs at 12 weeks. Moreover, CCs showed increased persistence, engraftment and specific markers expression compared to other groups. Their paracrine function was finally shown by increased capillary density and preserved cardiomyocyte size in the infarcted region [51].

The aggregation of cells into 3D-MTs prior to transplantation might be an improvement for current cardiac regenerative strategies $[52,53]$. Indeed, 3D-MTs are thought to enhance cell retention and engraftment thanks to the production of extracellular matrix. Their more physiological 3D environment is supposed to recapitulate the stem cell niche. 3D-MTs can also serve as new tools for coculture of multiple cell types [54]. They can contain mixed cell types, be coated with a different cell type, or be fused to produce Janus spheroids [55]. Interestingly, 3D co-culture of murine cardiomyocytes with endothelial cells or MSCs could constitute a remarkable model for the mechanisms of angiogenesis and vasculogenesis [56].

While therapies with MSCs and CSCs have proven to be safe and moderately efficient, the combination of these two cell types appears to enhance the individual effects of each cell type. This combinatorial approach is thus raising hope to achieve improved cardiac regeneration in future preclinical and clinical trials. Ingenious tools such as CCs and 3D-MTs composed of different cell types might help to unveil new routes toward successful cardiac stem cell therapy.

\section{Discussion}

The heart is well known to have a limited capacity for self-renewal. Therefore, cell-based therapies have been repeatedly suggested as a potential strategy for myocardial regeneration. While in initial preclinical and clinical studies, so-called unselected, firstgeneration cell types have only led to moderate and heterogeneous therapeutic effects, there is a clear need for so-called next-genera- tion stem cell therapies as well as combined approaches in order to enhance the regenerative potential of such regenerative therapies (fig. 1). Numerous cell populations have been evaluated in the translational setting presenting with a heterogeneous safety and efficacy profile. BMMSCs have proven to be safe and beneficial in preclinical as well as clinical settings [57]. CSCs/CPCs obtained from heart biopsies can be applied in a patient-specific manner, but their harvesting requires an invasive procedure, and their isolation and culture methods need to be improved. Although ESCs face ethical concerns, they have recently shown to be safe and efficient in preclinical and clinical studies $[36,37]$. While iPSCs represent a possible solution to overcome the ethical concerns raised by ESCs, they face immunological issues and bear teratogenic potential. Cardiac lineage commitment of the aforementioned cell types has been suggested as an effective way to improve the function of the diseased myocardium. Novel approaches such as guided cardiopoiesis and direct reprogramming into cardiomyocytes create cardiac-committed cellular therapeutics, which can match the target organ and prompt regeneration without the need of invasive biopsies. Moreover, these approaches could reduce or even eliminate immune rejection, and provide useful outcomes for creating not only a reasonable bench-to-bedside but also a reversed bed-tobench pathway, leading to the optimization of safety and efficacy issues of regenerative therapies [36].

A crucial issue in establishing more efficient cell-based therapies for ischemic heart disease is to understand the mechanisms that affect myocardial performance and that are inherent to each cell type [23]. Electrical coupling, differentiation, and paracrine signaling represent the most desired mechanisms. Therefore, combination therapies involving several cell types should be taken into consideration as these might induce synergistic and complementary effects on cardiac regeneration by combining different therapeutic mechanisms at a time. Also, depending on different cardiac pathologies, such as acute MI and chronic ischemic cardiomyopathy, the combination of different cell types might be required to obtain efficient outcomes $[50,58]$, especially because ischemic heart disease does not only affect muscular structure and function but also nervous, vascular and extracellular matrix structures. CCs and $3 \mathrm{D}$-MTs have recently emerged as combinatorial tools to mimic the physiological microenvironment of the target organ [51, 
56]. Another approach that is still unexplored and worth to be investigated is the repeated stem cell administration to the diseased area. Furthermore, the systematic comparison between autologous and allogeneic cell sources provides new insights into putative allogeneic off-the-shelf cell therapy products in the future. Allogeneic approaches would be beneficial to reduce technical and logistical challenges and accelerate the recovery process of the patients [59]. Standard operating procedures (SOPs) are needed for cell processing and expansion between cell harvesting and their implantation.

\section{Conclusion}

Although the regenerative properties of the heart are known to be limited, stem cell therapy holds great promise for the treatment of ischemic heart disease. While several studies have demonstrated the safety and feasibility of various cell sources and delivery modes over more than a decade in different clinical settings, recent studies have started focusing more on the improvement of the efficacy of cell therapy. However, the precise mode of repair, such as differentiation and paracrine signaling after cell transplantation, remains unclear. The first and most obvious obstacle is the identification of the optimal cell type for a successful translation into the clinical arena. Further issues such as the cell dose, delivery route, and timing remain to be solved, although it is suggested that higher cell numbers promote better outcomes [60]. Nevertheless, the appropriate dose depends most probably on the cell type, combinatorial products, donor age, and of course on the given cardiac pathology. Hence, ischemic heart disease might be treated with therapeutic cell products in the future, and patients might receive a unique and customized therapy according to their individual needs. However, the translational path leading to these outcomes is still long and requires GMP-compliant up-scaling and more valuable controlled trials.

\section{Acknowledgements}

The authors thank Mrs. De Simio from the University Hospital Zurich for excellent graphical support.

\section{Disclosure Statement}

The authors declare no conflict of interest.

\section{References}

1 World Health Organization: Cardiovascular Diseases (CVDS). 2015. www.who.int/cardiovascular_diseases/ en/ (last accessed July 6, 2016).

2 Jessup M, Brozena S: Heart failure. N Engl J Med 2003; 348:2007-2018.

$\checkmark 3$ Terzic A, Behfar A: Regenerative heart failure therapy headed for optimization. Eur Heart J 2014;35:12311234.

$\checkmark 4$ Mozid AM, Arnous S, Sammut EC, Mathur A: Stem cell therapy for heart diseases. Br Med Bull 2011;98: 143-159.

5 Behfar A, Crespo-Diaz R, Terzic A, Gersh BJ: Cell therapy for cardiac repair - lessons from clinical trials. Nat Rev Cardiol 2014;11:232-246.

6 Gyongyosi M, Wojakowski W, Lemarchand P, Lunde K, Tendera M, Bartunek J, Marban E, Assmus B, Henry TD, Traverse JH, Moye LA, Surder D, Corti R, Huikuri H, Miettinen J, Wohrle J, Obradovic S, Roncalli J, Malliaras K, Pokushalov E, Romanov A, Kastrup J, Bergmann MW, Atsma DE, Diederichsen A, Edes I, Benedek I, Benedek T, Pejkov H, Nyolczas N, Pavo N, Bergler-Klein J, Pavo IJ, Sylven C, Berti S, Navarese EP, Maurer G; ACCRUE Investigators: Meta-Analysis of Cell-based CaRdiac stUdiEs (ACCRUE) in patients with acute myocardial infarction based on individual patient data. Circ Res 2015;116: 1346-1360.

7 Durrani S, Konoplyannikov M, Ashraf M, Haider KH: Skeletal myoblasts for cardiac repair. Regen Med 2010; 5:919-932.

8 Williams AR, Hare JM: Mesenchymal stem cells: biology, pathophysiology, translational findings, and therapeutic implications for cardiac disease. Circ Res 2011; 109:923-940.
9 Hare JM, Fishman JE, Gerstenblith G, DiFede Velazquez DL, Zambrano JP, Suncion VY, Tracy M, Ghersin E, Johnston PV, Brinker JA, Breton E, DavisSproul J, Schulman IH, Byrnes J, Mendizabal AM, Lowery MH, Rouy D, Altman P, Wong Po Foo C, Ruiz P, Amador A, Da Silva J, McNiece IK, Heldman AW, George R, Lardo A: Comparison of allogeneic vs autologous bone marrow-derived mesenchymal stem cells delivered by transendocardial injection in patients with ischemic cardiomyopathy: the Poseidon randomized trial. JAMA 2012;308:2369-2379.

10 Heldman AW, DiFede DL, Fishman JE, Zambrano JP, Trachtenberg BH, Karantalis V, Mushtaq M, Williams AR, Suncion VY, McNiece IK, Ghersin E, Soto V, Lopera G, Miki R, Willens H, Hendel R, Mitrani R, Pattany P, Feigenbaum G, Oskouei B, Byrnes J, Lowery MH, Sierra J, Pujol MV, Delgado C, Gonzalez PJ, Rodriguez JE, Bagno LL, Rouy D, Altman P, Foo CW, da Silva J, Anderson E, Schwarz R, Mendizabal A, Hare JM: Transendocardial mesenchymal stem cells and mononuclear bone marrow cells for ischemic cardiomyopathy: The TAC-HFT randomized trial. JAMA 2014;311: 62-73.

11 Laflamme MA, Murry CE: Heart regeneration. Nature 2011;473:326-335.

12 Zhang Y, Mignone J, MacLellan WR: Cardiac regeneration and stem cells. Physiol Rev 2015;95:1189-1204.

13 Emmert MY, Hitchcock RW, Hoerstrup SP: Cell therapy, 3D culture systems and tissue engineering for cardiac regeneration. Adv Drug Deliv Rev 2014;69-70: 254-269.

14 Messina E, De Angelis L, Frati G, Morrone S, Chimenti S, Fiordaliso F, Salio M, Battaglia M, Latronico MV, Coletta M, Vivarelli E, Frati L, Cossu G, Giacomello A: Isolation and expansion of adult cardiac stem cells from human and murine heart. Circ Res 2004;95:911921.
15 Laugwitz KL, Moretti A, Lam J, Gruber P, Chen Y, Woodard S, Lin LZ, Cai CL, Lu MM, Reth M, Platoshyn O, Yuan JX, Evans S, Chien KR: Postnatal isl1+ cardioblasts enter fully differentiated cardiomyocyte lineages. Nature 2005;433:647-653.

16 Yee K, Malliaras K, Kanazawa H, Tseliou E, Cheng K, Luthringer DJ, Ho CS, Takayama K, Minamino N, Dawkins JF, Chowdhury S, Duong DT, Seinfeld J, Middleton RC, Dharmakumar R, Li D, Marban L, Makkar RR, Marban E: Allogeneic cardiospheres delivered via percutaneous transendocardial injection increase viable myocardium, decrease scar size, and attenuate cardiac dilatation in porcine ischemic cardio-

myopathy. PLoS One 2014;9:e113805.
17 Kanazawa H, Tseliou E, Malliaras K, Yee K, Dawkins JF, De Couto G, Smith RR, Kreke M, Seinfeld J, Middleton RC, Gallet R, Cheng K, Luthringer D, Valle I, Chowdhury S, Fukuda K, Makkar RR, Marban L, Marban E: Cellular postconditioning: Allogeneic cardiosphere-derived cells reduce infarct size and attenuate microvascular obstruction when administered after reperfusion in pigs with acute myocardial infarction. Circ Heart Fail 2015;8:322-332.

18 Lee ST, White AJ, Matsushita S, Malliaras K, Steenbergen C, Zhang Y, Li TS, Terrovitis J, Yee K, Simsir S, Makkar R, Marban E: Intramyocardial injection of autologous cardiospheres or cardiosphere-derived cells preserves function and minimizes adverse ventricular remodeling in pigs with heart failure post-myocardial infarction. J Am Coll Cardiol 2011;57:455-465.

19 Johnston PV, Sasano T, Mills K, Evers R, Lee ST, Smith RR, Lardo AC, Lai S, Steenbergen C, Gerstenblith G, Lange R, Marban E: Engraftment, differentiation, and functional benefits of autologous cardiosphere-derived cells in porcine ischemic cardiomyopathy. Circulation 2009;120:1075-1083, 1077 p following 1083. 
20 Bolli R, Chugh AR, D’Amario D, Loughran JH, Stoddard MF, Ikram S, Beache GM, Wagner SG, Leri A, Hosoda T, Sanada F, Elmore JB, Goichberg P, Cappetta D, Solankhi NK, Fahsah I, Rokosh DG, Slaughter MS, Kajstura J, Anversa P: Cardiac stem cells in patients with ischaemic cardiomyopathy (SCIPIO): initial results of a randomised phase 1 trial. Lancet 2011;378: 1847-1857.

21 Makkar RR, Smith RR, Cheng K, Malliaras K, Thomson LE, Berman D, Czer LS, Marban L, Mendizabal A, Johnston PV, Russell SD, Schuleri KH, Lardo AC, Gerstenblith G, Marban E: Intracoronary cardiospherederived cells for heart regeneration after myocardial infarction (CADUCEUS): a prospective, randomised phase 1 trial. Lancet 2012;379:895-904.

-22 Caplan AI, Dennis JE: Mesenchymal stem cells as trophic mediators. J Cell Biochem 2006;98:1076-1084

23 Segers VF, Lee RT: Stem-cell therapy for cardiac disease. Nature 2008;451:937-942.

24 Wollert KC, Drexler H: Clinical applications of stem cells for the heart. Circ Res 2005;96:151-163.

25 Mazo M, Arana M, Pelacho B, Prosper F: Mesenchymal stem cells and cardiovascular disease: a bench to bedside roadmap. Stem Cells Int 2012;2012:175979.

26 Bartunek J, Behfar A, Dolatabadi D, Vanderheyden M, Ostojic M, Dens J, El Nakadi B, Banovic M, Beleslin B, Vrolix M, Legrand V, Vrints C, Vanoverschelde JL, Crespo-Diaz R, Homsy C, Tendera M, Waldman S, Wijns W, Terzic A: Cardiopoietic stem cell therapy in heart failure: The C-CURE (Cardiopoietic stem Cell therapy in heart failURE) multicenter randomized trial with lineage-specified biologics. J Am Coll Cardiol 2013;61:2329-2338.

27 Bartunek J, Davison B, Sherman W, Povsic T, Henry TD, Gersh B, Metra M, Filippatos G, Hajjar R, Behfar A, Homsy C, Cotter G, Wijns W, Tendera M, Terzic A Congestive Heart Failure Cardiopoietic Regenerative Therapy (CHART-1) trial design. Eur J Heart Fail 2016;18:160-168.

28 Sato N: Lessons and perspectives on heart failure management from considerations based on the CHART-2 study. Circ J 2015;79:1689-1690.

29 Garry DJ, Olson EN: A common progenitor at the heart of development. Cell 2006;127:1101-1104.

30 Murry CE, Keller G: Differentiation of embryonic stem cells to clinically relevant populations: lessons from embryonic development. Cell 2008;132:661-680.

31 Nussbaum J, Minami E, Laflamme MA, Virag JA, Ware CB, Masino A, Muskheli V, Pabon L, Reinecke H, Murry CE: Transplantation of undifferentiated murine embryonic stem cells in the heart: teratoma formation and immune response. FASEB J 2007;21:1345-1357.

32 Huber I, Itzhaki I, Caspi O, Arbel G, Tzukerman M, Gepstein A, Habib M, Yankelson L, Kehat I, Gepstein L: Identification and selection of cardiomyocytes during human embryonic stem cell differentiation. FASEB J 2007;21:2551-2563.

-33 Tomescot A, Leschik J, Bellamy V, Dubois G, Messas E, Bruneval P, Desnos M, Hagege AA, Amit M, Itskovitz J, Menasche P, Puceat M: Differentiation in vivo of cardiac committed human embryonic stem cells in postmyocardial infarcted rats. Stem Cells 2007;25: 2200-2205.

-34 Behfar A, Perez-Terzic C, Faustino RS, Arrell DK, Hodgson DM, Yamada S, Puceat M, Niederlander N, Alekseev AE, Zingman LV, Terzic A: Cardiopoietic programming of embryonic stem cells for tumor-free heart repair. J Exp Med 2007;204:405-420.

35 Laflamme MA, Chen KY, Naumova AV, Muskheli V, Fugate JA, Dupras SK, Reinecke H, Xu C, Hassanipour M, Police S, O'Sullivan C, Collins L, Chen Y, Minami E, Gill EA, Ueno S, Yuan C, Gold J, Murry CE: Cardiomyocytes derived from human embryonic stem cells in pro-survival factors enhance function of infarcted rat hearts. Nat Biotechnol 2007;25:1015-1024.
36 Menasche P, Vanneaux V, Fabreguettes JR, Bel A, Tosca L, Garcia S, Bellamy V, Farouz Y, Pouly J, Da mour O, Perier MC, Desnos M, Hagege A, Agbulut O, Bruneval P, Tachdjian G, Trouvin JH, Larghero J: Towards a clinical use of human embryonic stem cell-derived cardiac progenitors: a translational experience. Eur Heart J 2015;36:743-750.

37 Menasche P, Vanneaux V, Hagege A, Bel A, Cholley B, Cacciapuoti I, Parouchev A, Benhamouda N, Tachdjian G, Tosca L, Trouvin JH, Fabreguettes JR, Bellamy V, Guillemain R, Suberbielle Boissel C, Tartour E, Desnos M, Larghero J: Human embryonic stem cellderived cardiac progenitors for severe heart failure treatment: first clinical case report. Eur Heart J 2015; 36:2011-2017.

38 Bellin M, Marchetto MC, Gage FH, Mummery CL: Induced pluripotent stem cells: the new patient? Nat Rev Mol Cell Biol 2012;13:713-726.

39 Kawamura M, Miyagawa S, Miki K, Saito A, Fukushima S, Higuchi T, Kawamura T, Kuratani T, Daimon T, Shimizu T, Okano T, Sawa Y: Feasibility, safety, and therapeutic efficacy of human induced pluripotent stem cell-derived cardiomyocyte sheets in a porcine ischemic cardiomyopathy model. Circulation 2012; 126(11 suppl 1):S29-37.

40 Ye L, Chang YH, Xiong Q, Zhang P, Zhang L, Somasundaram P, Lepley M, Swingen C, Su L, Wendel JS, Guo J, Jang A, Rosenbush D, Greder L, Dutton JR, Zhang J, Kamp TJ, Kaufman DS, Ge Y, Zhang J: Cardiac repair in a porcine model of acute myocardial infarction with human induced pluripotent stem cellderived cardiovascular cells. Cell Stem Cell 2014;15: 750-761.

41 Lalit PA, Salick MR, Nelson DO, Squirrell JM, Shafer CM, Patel NG, Saeed I, Schmuck EG, Markandeya YS, Wong R, Lea MR, Eliceiri KW, Hacker TA, Crone WC, Kyba M, Garry DJ, Stewart R, Thomson JA, Downs KM, Lyons GE, Kamp TJ: Lineage reprogramming of fibroblasts into proliferative induced cardiac progenitor cells by defined factors. Cell Stem Cell 2016;18:354-367.

42 Birket MJ, Ribeiro MC, Verkerk AO, Ward D, Leitoguinho AR, den Hartogh SC, Orlova VV, Devalla HD, Schwach V, Bellin M, Passier R, Mummery CL: Expansion and patterning of cardiovascular progenitors derived from human pluripotent stem cells. Nat Biotechnol 2015;33:970-979.

43 Doppler SA, Deutsch MA, Lange R, Krane M: Direct reprogramming-the future of cardiac regeneration? Int J Mol Sci 2015;16:17368-17393.

44 Ieda M, Fu JD, Delgado-Olguin P, Vedantham V, Hayashi Y, Bruneau BG, Srivastava D: Direct reprogramming of fibroblasts into functional cardiomyocytes by defined factors. Cell 2010;142:375-386.

45 Song K, Nam YJ, Luo X, Qi X, Tan W, Huang GN, Acharya A, Smith CL, Tallquist MD, Neilson EG, Hill JA, Bassel-Duby R, Olson EN: Heart repair by reprogramming non-myocytes with cardiac transcription factors. Nature 2012;485:599-604.

46 Qian L, Huang Y, Spencer CI, Foley A, Vedantham V, Liu L, Conway SJ, Fu JD, Srivastava D: In vivo reprogramming of murine cardiac fibroblasts into induced cardiomyocytes. Nature 2012;485:593-598.

47 Ebert AD, Diecke S, Chen IY, Wu JC: Reprogramming and transdifferentiation for cardiovascular development and regenerative medicine: where do we stand? EMBO Mol Med 2015;7:1090-1103.

48 Hatzistergos KE, Quevedo H, Oskouei BN, Hu Q, Feigenbaum GS, Margitich IS, Mazhari R, Boyle AJ, Zambrano JP, Rodriguez JE, Dulce R, Pattany PM, Valdes D, Revilla C, Heldman AW, McNiece I, Hare JM: Bone marrow mesenchymal stem cells stimulate cardiac stem cell proliferation and differentiation. Circ Res 2010;107:913-922.
49 Williams AR, Hatzistergos KE, Addicott B, McCall F, Carvalho D, Suncion V, Morales AR, Da Silva J, Sussman MA, Heldman AW, Hare JM: Enhanced effect of combining human cardiac stem cells and bone marrow mesenchymal stem cells to reduce infarct size and to restore cardiac function after myocardial infarction. Circulation 2013;127:213-223.

50 Karantalis V, Suncion-Loescher VY, Bagno L, Golpanian S, Wolf A, Sanina C, Premer C, Kanelidis AJ, McCall F, Wang B, Balkan W, Rodriguez J, Rosado M, Morales A, Hatzistergos K, Natsumeda M, Margitich I, Schulman IH, Gomes SA, Mushtaq M, DiFede DL, Fishman JE, Pattany P, Zambrano JP, Heldman AW, Hare JM: Synergistic effects of combined cell therapy for chronic ischemic cardiomyopathy. J Am Coll Cardiol 2015;66:1990-1999.

51 Quijada P, Salunga HT, Hariharan N, Cubillo JD, ElSayed FG, Moshref M, Bala KM, Emathinger JM, De La Torre A, Ormachea L, Alvarez R Jr, Gude NA, Sussman MA: Cardiac stem cell hybrids enhance myocardial repair. Circ Res 2015;117:695-706.

52 Emmert MY, Wolint P, Wickboldt N, Gemayel G, Weber B, Brokopp CE, Boni A, Falk V, Bosman A, Jaconi ME, Hoerstrup SP: Human stem cell-based three-dimensional microtissues for advanced cardiac cell therapies. Biomaterials 2013;34:6339-6354.

53 Emmert MY, Wolint P, Winklhofer S, Stolzmann P, Cesarovic N, Fleischmann T, Nguyen TD, Frauenfelder T, Boni R, Scherman J, Bettex D, Grunenfelder J, Schwartlander R, Vogel V, Gyongyosi M, Alkadhi H, Falk V, Hoerstrup SP: Transcatheter based electromechanical mapping guided intramyocardial transplantation and in vivo tracking of human stem cell based three dimensional microtissues in the porcine heart. Biomaterials 2013;34:2428-2441.

54 Gunter J, Wolint P, Bopp A, Steiger J, Cambria E, Hoerstrup SP, Emmert MY: Microtissues in cardiovascular medicine: regenerative potential based on a 3D microenvironment. Stem Cells Int 2016;2016:9098523.

55 Hsiao AY, Tung YC, Qu X, Patel LR, Pienta KJ, Takayama S: 384 hanging drop arrays give excellent $z$-factors and allow versatile formation of co-culture spheroids. Biotechnol Bioeng 2012;109:1293-1304.

56 Garzoni LR, Rossi MI, de Barros AP, Guarani V, Keramidas M, Balottin LB, Adesse D, Takiya CM, Manso PP, Otazu IB, Meirelles Mde N, Borojevic R: Dissecting coronary angiogenesis: 3D co-culture of cardiomyocytes with endothelial or mesenchymal cells. Exp Cell Res 2009;315:3406-3418.

57 Strauer BE, Steinhoff G: 10 years of intracoronary and intramyocardial bone marrow stem cell therapy of the heart: from the methodological origin to clinical practice. J Am Coll Cardiol 2011;58:1095-1104

58 Dixit P, Katare R: Challenges in identifying the best source of stem cells for cardiac regeneration therapy. Stem Cell Res Ther 2015;6:26.

59 Jansen Of Lorkeers SJ, Eding JE, Vesterinen HM, van der Spoel TI, Sena ES, Duckers HJ, Doevendans PA, Macleod MR, Chamuleau SA: Similar effect of autologous and allogeneic cell therapy for ischemic heart disease: systematic review and meta-analysis of large animal studies. Circ Res 2015;116:80-86.

60 Pavo N, Charwat S, Nyolczas N, Jakab A, Murlasits Z, Bergler-Klein J, Nikfardjam M, Benedek I, Benedek T, Pavo IJ, Gersh BJ, Huber K, Maurer G, Gyongyosi M: Cell therapy for human ischemic heart diseases: critical review and summary of the clinical experiences. J Mol Cell Cardiol 2014;75:12-24. 